\title{
Developing Mental Health Services in the Global South
}

\author{
Suman Fernando
}

Faculty of Social Sciences and Humanities, London Metropolitan University, London, UK

\begin{abstract}
This paper outlines the diversity of medical and healing systems indigenous to many regions of the world and their under-development and suppression during colonialism; describes briefly social and cultural changes that have taken place in the Global South after de-colonisation, resulting in varying degrees of a plurality (in terms of cultural style) of mental health systems currently available; summarizes important general principles of postcolonial development in the Global South; and, finally, points to ways of mental health and wellbeing development in the Global South by drawing on the example of Sri Lanka where the author was involved in a four-year research and capacity building project between 2007 and 2012. The paper takes a historical postcolonial approach to development on the principals of sustainability and cultural relevance and argues for a pragmatic approach in the short term while building up a body of knowledge about the countries concerned, their ground realities and their indigenous psychologies.
\end{abstract}

\section{Key words}

Post-colonial; bottom-up; cultural diversity; indigenous

\section{Introduction}

After the end of the second world war and fall of European empires in Asia and Africa there was a realisation that economic development, as well as improvement of living standards and personal health were required in many parts of the Global South; and international bodies such as the World Health Organization (WHO) were founded to promote such development. Since then there has been much contentious debate about what types of services are best suited to promoting mental health in countries of the Global South; the nature and backgrounds of the dominant players in such development; how the needs of those who would eventually use the services should be assessed; and whether (and if so how) their wishes about the cultural style of services should be respected; and so on. This paper considers the practical problems of implementing development (and how they may be addressed) by exploring the epistemology of knowledge about matters to do with 'mind' and 'health'; the different ways in which people with problems of living have been helped over the years; and the political realities of power that play out in the world of today.

\section{Systems of mental health care worldwide}

The European Enlightenment of the seventeenth and eighteenth centuries led to cultural changes in Europe resulting in people seen as 'mad' (the insane), together with others also considered socially undesirable, being confined to asylums in large numbers - 'the great confinement' (Foucault, 1967, p. 38) - and subsequently the study of 'madness' by medical doctors, and later, psychologists leading to the disciplines of psychiatry and clinical psychology, referred to as the 'psy disciplines' by McAvoy (2014). A language developed around these peculiarly 'Western' knowledge systems, generating words / concepts such as 'mental health', 'mental illness' and 'psychotherapy', now used globally but often interpreted differently in non-Western cultural settings. 
Notions of 'mind' and its correlates such as beliefs and emotional distress, as well as issues that people had in interacting with each other-in fact the understanding of the human condition and problems of living and interacting - developed very differently in nonWestern cultural traditions including that in the Islamic world (see later), compared to those in the West (see Fernando, 2002; Fernando \& Moodley, 2018; Gaines, 1984; Hammer, 1990; Kleinman and Good, 1985; Marsella and White, 1982). Ways of thinking ('cultures') change as a result of cross-cultural interaction between peoples - Hacking (1995) calls this a "looping effect" (title) - especially when there is aggressive domination of one or other group (as happened in colonialism and mass enslavement); yet, some basic cultural patterns still stay the same. Even today in parts of the Global South, human problems of living, especially those accompanied by emotional distress, attributed in the Global North to illness of the 'mind', are interpreted in a variety of other ways - social, personal, spiritual and so on; and few are attributed to 'illness' as such. For example, the system for healing of madness within the Tibetan medical tradition, described as 'a complex interweaving of religion, mysticism, psychology, and rational medicine' (Clifford, 1984, p. 7) still persists — or at least was evident in the early 1980s when Terry Clifford conducted her research; and some aspects of the therapeutic approach in the mãristãns (Arabic mental hospitals - Dols, 1992) that thrived between during the middle-ages and described by Graham (1967) as 'a blissful union of science and religion' (p. 47) and by Foucault (2006) as 'a sort of spiritual therapy ... involving music dance, and theatrical spectacles and readings of marvellous stories' (p. 117) are still discernible (El-Islam, 1982; El-Khayat, 1997).

\section{Recent changes in the Global South}

Western systems of mental health ('asylum psychiatry') were imposed in some regions of the Global South during colonialism, but had little cultural impact of a lasting nature on ways of thinking among native people of the countries concerned (Fernando, 2014, pp. 63-79). But (Western) bio-medical psychiatry aggressively promoted since the 1970 s together with the use of psychotropic medication and 'talking therapies' - at first via non-governmental organisations (NGOs) funded by resources from Western donors - and latterly supported by the Movement for Global Mental Health (MGMH) (Collins et al. 2011; Horton, 2007; LSHTM, 2013; Patel \& Prince, 2010) - show signs of having a lasting effect on the thinking of local people (their 'cultures') (see Fernando, 2014, pp. 107-114; Watters, 2011). In practical terms, the result is that in many parts of the Global South, a plurality of mental health systems are in place - Western systems, traditional indigenous systems, new, innovative systems, and those that attempt to adapt Western systems to make them 'culturally sensitive' to local norms.

\section{Principles of development in the Global South}

Mental health development - better called "mental health and wellbeing promotion" (see Fernando, 2014, pp.146-7) — in the Global South should be seen as part and parcel of general development, especially that aimed at poverty reduction and empowerment of people at the bottom of the pile, socially and politically. What is important is that new services as they develop should be brought into being in an organised way in close consultation with local people and reflect local cultural norms including psychologies of local people as closely as possible — here 'psychologies' mean 'stories of the self in time ... that explain the basis of our actions' (Kirmayer, Adeponle, \& Dzokoto, 2018, p. 163). Services should aim at being ethical - for the benefit of people 'as self-defining subjects' rather than 'objects of concern ... entitled so choose their way of life themselves' (Gasper, 2004, p. 195, italics in original) and sustainable - that is not dependent on external (Western) training and input (O'Riordan, 1988; Warburton, 1998). Together with such development there needs to be action to address 
social determinants of health and issues of regulation and good governance of services; and care should be taken to protect vulnerable communities from exploitation by big business.

\section{Developing mental health services in the Global South}

Since many parts of the Global South are beset by serous socio-political problems, a word of caution voiced by Kirmayer (2006) is worth noting:

'There is a danger that focusing attention on mental health needs only serves to divert attention from more difficult social problems that demand political and economic solutions. Psychiatry may collude with those who benefit from the status quo, neutralizing political challenges by reframing problems as aspects of individual mental health and offering treatment to individuals who are, after all, expressing the pain of a system out of joint' ( $p$. 138). If we turn to the literature for guidance, there are major problems in what is often written up as 'cross cultural research': Nearly all the 'knowledge' that the psy disciplines draw on, especially diagnostic categories, ways of psychological assessment, 'pathologies' indicative of disorders or illnesses, models of therapy quoted as 'evidence based', together constitute a major problem — the 'category fallacy' (first described by Kleinman, 1977), which means the imposition of a concept/category derived in one socio-cultural setting across cultures. And differences in health-seeking practices and illness behaviour that varies widely worldwide often distort what is 'found'.

The lack of reliable meaningful research data is a major drawback, but some pointers on how we should go about mental health development are given in the next three paragraphs:

A research project carried out by WHO $(1973,1979)$ in the 1960 s, measured illnessoutcomes of people in several regions of the world who had been diagnosed as suffering from 'schizophrenia' and assessed over 13 - 17 years (Hopper and Wanderling, 2000; Sartorius et al. 1986). The cohorts of patients in India and Nigeria had better outcomes compared to cohorts in the UK and USA, both in terms of symptom relief and social recovery - although the former had been exposed to little in the way of psychiatric treatment and after-care.

A study in the early 2000s (Raguram, Venkateswaram, Ramakrishna, \& Weiss, 2002) described outcomes of people who had attended a Hindu temple in South India known for helping people with mental health problems. The researchers found that most suffered from psychotic illness and showed a degree of improvement (judged by reduction of symptoms and their own expressed views) that matched improvement that may be expected as a result of bio-medical therapy, although no drugs had been given to them at the temple.

Haliburton (2004) reported a study of 100 people, all with problems that amounted to a diagnosis of schizophrenia, who had accessed one or more of three forms of therapy in Kerala (South India), namely Ayurvedic medicine, bio-medical psychiatry and religious healing at one or other of three locations with reputations for healing people with mental illness - a Hindu temple, Muslim mosque and Christian church — to find that similar proportions benefitted from each form of therapy.

\section{Pragmatic approach to development in the short term}

This section of the paper is based on the author's experience while working as a psychiatrist in multicultural areas of London (UK) and previously in Sri Lanka; observations of the work of NGOs in Toronto (Canada) and London; and findings of a research and capacity building 
program in Sri Lanka during 2007 and $2012^{1}$. The Sri Lankan workers in the program (described in detail by Weerackody and Fernando, 2011) investigated community perceptions of wellbeing and coping strategies adopted in times of crisis; and members of the team had the opportunity of visiting religious centres of healing, meeting with indigenous healers as well as participating in 'capacity building' programs with community workers and professional staff at psychiatric and community centres. As a result, they obtained a grasp of what was being done (and not done) in the field of mental health and wellbeing; and how local people viewed the services that were being provided.

The team concluded that, in planning mental health and wellbeing services for a region or locality, the first step is to take note of ground realities in the region concerned. They learned that in planning development, it is important first to get to know the nature of the lives of local people and the ways in which local people seek help; and at all stages of development to think local, looking for ways of embedding any new services in local institutions and communities. An assumption that there are no services for mental health and wellbeing in a particular locality came about sometimes because there was nothing that carried the label 'health', 'mental health' or 'madness'; but this was shown to be false once services were identified that people access when experiencing personal or psychological problems - clearly, these constituted services for mental health and wellbeing.

\section{Conclusions}

For long term planning, information from focused and sensitive research carried out in the Global South under local direction that yields meaningful conclusions is required. The hard data sought should include: (a) Efficacy of systems as seen by service users; (b) knowledge of local practices (especially religious approaches and indigenous medicine); (c) idioms of distress and ways of identifying social stress; (d) how individuals and communities cope with social problems, distress, disability, and so on. But to be politically realistic, we cannot wait for the long term. We have to get on with development now as far as possible.

In the short term, the aim of all agencies seeking to develop mental health services must be to enable local people to develop services that are ethical, that is for the benefit of the people concerned as subjects rather than objects of development, and sustainable without dependence on rich countries in the West. The best way of doing this is to adopt (and possibly adapt) the approach of community development described by Chambers (1992, 1997, 2005) which essentially means working bottom-up with whatever stakeholders are available, taking on board the fact that (as observed in Sri Lanka) ordinary people in most parts of the Global South get the best help (for mental health and wellbeing) from family, indigenous healers and socio-cultural community systems in the community (including religious or semi-religious agencies); and, if given the choice, want to access such services, as well as some aspects (not all) of Western-type psychiatric services - the choice being left to service users and their families. The greatest impediment to getting the help needed is poverty and/or lack of social support, whether from family or the state. This needs to be redressed if meaningful mental health development of services is to be undertaken,

\footnotetext{
${ }^{1}$ Jointly implemented by the People's Rural Development Association (PRDA) in Sri Lanka and McGill University and the Douglas Mental Health University Institute at Montreal with support from the Global Health Research Initiative (GHRI), a collaborative research funding partnership of the Canadian organisations
} 


\section{References}

Chambers, R. (1992). Rural appraisal: Rapid, relaxed and participatory, institute of development studies (IDS), Discussion Paper 311. Brighton, Sussex, UK: IDS.

Chambers, R. (1997). Whose reality counts? Putting the first last. London, UK: ITDG Publishing.

Chambers, R. (2005). Us and them: Finding a new paradigm for professionals. In D. Warburton (Ed.), Community and sustainable development: Participation in the future (pp.117-147). London, UK: Earthscan Publications.

Clifford, T. (1984). Tibetan Buddhist medicine and psychiatry: The diamond healing. York Beach, ME: Samuel Weiser.

Collins, P. Y., Patel, V., Joestl, S. S., March, D., Insel, T. R. and Daar, A. S., ... Walport, M. (2011). Grand challenges in global mental health, Nature, 475(7354), 27-30. doi:10.1038/475027a.

Dols, M. W. (1992). Majnün: The madman in Medieval Islamic Society. In D. E. Immisch (Ed.). Oxford, UK: Clarendon Press.

El-Islam, M. F. (1982.) Arabic cultural psychiatry Transcultural Psychiatric Research Review 19(1), 5-24. doi:10.1177/136346158201900101.

El-Khayat, G. (1997) For anthropology of knowledge in Arab-Muslim culture. Transcultural Psychiatry 34(1), 58-69. doi:10.1177/136346159703400105.

Fernando, S. (2002). Mental health, race and culture (2nd ed.). Basingstoke, UK; New York, NY: Palgrave.

Fernando, S. (2014). Mental health worldwide; culture, globalization and development. Basingstoke, UK; New York, NY: Palgrave Macmillan.

Fernando, S. \& Moodley, R. (2018). Introduction. In S. Fernando \& R. Moodley (Eds.), Global psychologies, mental Health and the global south (pp. 1-17). London, UK: Palgrave Macmillan, part of Springer Nature.

Fernando, S. \& Weerackody, C. (2011). Aspects of mental health in Sri Lanka. Colombo, Sri Lanka: People's Rural Developmental Association (PRDA).

Foucault, M. (1967). Madness and civilization. A history of insanity in the age of reason London: Tavistock. Originally published in French as Histoire de la Folie. Paris: Libraire Plon 1961.

Foucault, M. (2006). History of madness. In Jean Khalfa, trans. Jonathan Murphy \& Jean Khalfa (Eds.). London, UK New York, NY: Routledge.

Gaines, A. D. (1984). Cultural definitions, behaviour and the person in American Psychiatry. In A. J. Marsella \& G. M. White (Eds.), Cultural conceptions of mental health and therapy (pp. 167-92). Dordrecht, The Netherlands: Reidel.

Gasper, D. (2004). The ethics of development from economism to human development. Edinburgh, UK: Edinburgh University Press.

Graham, T. F. (1967). Medieval minds, mental health in the middle ages. London, UK: Allen \& Unwin. 
Hacking, I. (1995). The looping effects of human kinds. in D. Sperber, D. Premark, \& A. J. Premark (Eds.), Causal cognition: A multidisciplinary approach (pp. 351-383). Oxford, UK: Oxford University Press.

Halliburton, M. (2004). Finding a fit: Psychiatric pluralism in South India and its implications for WHO studies of mental disorder. Transcultural Psychiatry 41(1), 80-98. doi:10.1177/1363461504041355.

Hammer, L. (1990). Dragon rises, red bird flies. Psychology and Chinese Medicine. New York, NY: Station Hill Press.

Hopper, K. and Wanderling, J. (2000). 'Revisiting the developed versus developing country distinction in course and outcome in schizophrenia: Results from ISoS, the world collaborative follow up project', Schizophrenia Bulletin, 26(4), 835-46. doi:10.1093/oxfordjournals.schbul.a033498.

Horton R. (2007). Launching a new movement for mental health. The Lancet, 370(9590), 806. doi:10.1016/S0140-6736(07)61243-4.

Kirmayer, L. J. (2006). Beyond the "New Cross-cultural psychiatry", cultural biology, discursive psychology and the ironies of globalisation, Transcultural Psychiatry 43(1), 126-144. doi:10.1177/1363461506061761.

Kirmayer, L. J., Adeponle, A. \& Dzokoto, V. A. A. (2018). Varieties of global psychology: Cultural diversity and construction of the self, in S. Fernando \& R Moodley (Eds.), Global psychologies, mental health and the global South (pp. 21-37). London, UK: Palgrave Macmillan, part of Springer Nature,

Kleinman, A. (1977). Depression, somatization and the "new cross cultural psychiatry". Social Science \& Medicine (1967, 11(1), 3-10. doi:10.1016/0037-7856(77)90138-X.

Kleinman, A. and Good, B. (1985). Culture and depression studies in the anthropology and cross-cultural psychiatry of affect and disorder. Berkeley, CA: University of California Press.

LSHTM (London School of Hygiene and Tropical Medicine). (2013). Gift establishes nine new scholarships for global mental health' LSHTM. Retrieved from: http://www.lshtm.ac.uk/newsevents/news/2013/nine_new_scholarships.html.

Marsella, A. J. \& White, G. M. (Eds.) (1982). Cultural conceptions of mental health and Therapy. Dordrecht: Reidel.

McAvoy J. (2014). Psy Disciplines. In: T. Teo (ed.). Encyclopedia of critical psychology (pp. 1527-1529). New York, NY: Springer.

O'Riordan, T. (1988). Civil science and the sustainability transition in D. Warburton (Ed.), Community and sustainable development: Participation in the future (pp. 96-116). London, UK: Earthscan Publications.

Patel, V., and Prince, M. (2010). Global mental health. A new global health field comes of age, JAMA, 303(19), 1976-77. doi:10.1001/jama.2010.616.

Raguram, R., Venkateswaram, A., Ramakrishna, J., \& Weiss, M. (2002). 'Traditional community resources for mental health: A report of temple healing from India', $B M J$, 325(7354), 38-40. doi:10.1136/bmj.325.7354.38.

Sartorius, N., Jablensky, A., Korten, A., Ernberg, G., Anker, M., Cooper, J. E. \& Day, R. (1986) Early manifestations and first-contact incidence of schizophrenia in different cultures: A preliminary report on the initial evaluation phase of the WHO 
collaborative study on determinants of outcome of severe mental disorders. Psychological Medicine, 6, 909-28. doi:10.1017/S0033291700011910.

Warburton, D. (1998). A passionate dialogue: Community and sustainable development. In D. Warburton (Ed.), Community and sustainable development Participation in the Future. (pp.1-39), London, UK: Earthscan Publications.

Watters, E. (2011) Crazy like us; the globalization of the western mind. London, UK: Constable and Robinson.

WHO (World Health Organization) (1973). Report of the international pilot study of schizophrenia (Vol. 1). Geneva, Switzerland: WHO.

WHO (World Health Organization) (1979). Schizophrenia: An international follow-up study. London, UK: Wiley.

The author notes no conflict of interest in connection with this article 